\title{
Enhancement and identification of dust events in the south-west region of Iran using satellite observations
}

\author{
F TAghavi ${ }^{1}$, E OWlad $^{1,2, *}$ and S A ACKerman ${ }^{3}$ \\ ${ }^{1}$ Institute of Geophysics, University of Tehran, Tehran, Iran. \\ ${ }^{2}$ Department of Atmospheric Science, Iranian National Institute for Oceanography and Atmospheric Science, \\ Tehran, Iran. \\ ${ }^{3}$ Department of Atmospheric and Oceanic Sciences, University of Wisconsin, Madison, USA. \\ *Corresponding author.e-mail: e.owlad@inio.ac.ir
}

South-west Asia including the Middle East is one of the most prone regions to dust storm events. In recent years, there was an increase in the occurrence of these environmental and meteorological phenomena. Remote sensing could serve as an applicable method to detect and also characterise these events. In this study, two dust enhancement algorithms were used to investigate the behaviour of dust events using satellite data, compare with numerical model output and other satellite products and finally validate with in-situ measurements. The results show that the use of thermal infrared algorithm enhances dust more accurately. The aerosol optical depth from MODIS and output of a Dust Regional Atmospheric Model (DREAM8b) are applied for comparing the results. Ground-based observations of synoptic stations and sun photometers are used for validating the satellite products. To find the transport direction and the locations of the dust sources and the synoptic situations during these events, model outputs (HYSPLIT and NCEP/NCAR) are presented. Comparing the results with synoptic maps and the model outputs showed that using enhancement algorithms is a more reliable way than any other MODIS products or model outputs to enhance the dust.

\section{Introduction}

Dust storms are a kind of severe natural disaster in dust source regions, which have a negative impact on human health, and industrial products and activities. According to the WMO's definition, the dust storm is reported when the surface visibility reduces below $1000 \mathrm{~m}$ by strong dust-raising winds. Dust storms generate mainly in windy, dust-rich arid and semiarid areas, such as in North Africa, South-west Asia, South-west USA and ChinaMongolia (Thomas 1997). Countries located in the arid and semi-arid belt of the world including Iran suffer from dust events. In recent years, these events have been the main hazards in areas of South-west Asia and repeated droughts and possible results of climate variability such as desertification have brought dust storms to the attention of many scientists (Jamalizadeh et al. 2008; Taghavi and Mohammadi 2008). Several complex dust storms have recently occurred in the southwestern part of Iran (e.g., 25th March 2003, 17th April 2003, 17th May 2007, 20th May 2010, 4th March 2011, 27th January 2015, and 10th February 2015), which caused huge damage and imposed negative impacts on traffic, air quality, and people's daily life in local and downstream areas. As a consequence of these events, the numbers of associated health, economic, and environmental effects have been raised by the increasing intensity

Keywords. MODIS; dust storm; visible; infrared; remote sensing; brightness temperature. 
of these storms (Edgell 2006). Miri et al. (2007) reported that during dust storms in Sistan, located on the eastern border of Iran, the number of respiratory patients increased significantly, especially those affected by chronic obstructive pulmonary diseases and asthma.

Furthermore, dust particles are the primary aerosols influencing global climate change through direct and indirect radiation forcing. Therefore, the real-time monitoring of dust storms is extremely important for environmental research in the southwest Asia region. For high temporal and spatial scales, satellite remote sensing may serve as an ideal technique for studying the lifecycle of dust storms including their generation, development and decay.

Middleton (1986) has used ground station observations to examine the frequency and seasonality of dust storms in south-west Asia. The results from past studies suggest that south-west Asia is one of the most important dust raising areas in the world, exceeded in importance only by the Sahara, Arabia and the Taklamakan Desert of China (Washington et al. 2003).

Since the 1970s, scientists have used two different techniques, namely the VIR (visible and near infrared) and the window of the TIR (thermal infrared) to identify the occurrence of dust storms. Shenk and Curran (1974) used the Nimbus-THIR (temperature humidity infrared radiometer) 11 $\mu \mathrm{m}$ brightness temperature to differentiate the dust in the atmosphere from desert surface based on the severe daytime temperature gradients in the boundary layer. This one-channel method is limited because changes in surface emissivity lead to brightness temperature changes and, therefore, clouds can often be misinterpreted as dust. In order to carry out this procedure, researchers have studied dust storms by means of different satellite images, such as Landsat TM/ETM (Fraser 1976), METEOSAT data (Wald et al. 1998; Legrand et al. 2001) and NOAA-AVHRR (Janugani et al. 2009). Earlier researchers used the visible spectrum to monitor dust outbreaks as well as to estimate dust optical depth over oceanic regions (Carlson 1979; Norton et al. 1980). However, monitoring dust aerosol outbreaks over land using satellite visible and near-infrared data is difficult due to the bright underlying desert surface. The 1996 version of the MODIS-aerosol algorithm (Algorithm Theoretical Basis Document, ATBD-96: Ackerman et al. 2002) introduced the rationale for performing aerosol remote sensing from MODIS on a global scale.

Because dust storms mostly occur over desert or arid regions with bright surfaces, such as the Sahara Desert, the surface contribution to the satellite signal is quite large and often unknown. As a result, estimates of the properties of dust aerosol are highly uncertain (Zhang et al. 2006). Zhao et al. (2010) introduced a detection algorithm of dust and smoke for application to satellite multi-channel imagers. The main advantage of Blowing Dust Enhancement imagery over conventional single-channel imagery is the ability to make a rapid assessment of dust in the scene.

The TIR region is of great importance to surficial geologic research as the amount of energy emitted from minerals and rocks can be interpreted to reveal their properties. Although the TIR region spans the 3-50 $\mu \mathrm{m}$ wavelengths, absorption and scattering by water vapour, carbon dioxide and ozone limit the amount of information available in that region. The exception is the $8-12 \mu \mathrm{m}$ region, where there is $80-$ 90\% transmission, and where silicate minerals have unique spectral features (King et al. 1992, 1999; Ramsey and Fink 1999; Mohammad 2012). Redha Mohammad (2012) used TIR techniques, by creating a fine-grained $(2.7-45 \mu \mathrm{m})$ mineral spectral library, direct laboratory emission spectroscopic analysis, and spectral and image deconvolution models, to characterise both the mineral content and particle size of dust storms affecting Kuwait. His results were validated using a combination of X-ray diffraction (XRD) and scanning electron microscopy (SEM) analyses that were performed on dust samples for three dust storms (May and July 2010, March 2011) from Kuwait. A combination of forward and backward Hybrid Single-Particle Lagrangian Integrated Trajectory (HYSPLIT) models were also used to track air parcels arriving in Kuwait at the time of dust storm sample collection, thus testing the link to dust emitting areas or hotspots in eastern Syria and western Iraq. World soil maps and TIR analysis of surface deposits of these potential hotspots support this interpretation and identified areas of high calcite concentration. This interpretation was in agreement with prior studies identifying calcite as the major mineral in dust storms affecting Kuwait. Spectral and image deconvolution models provided good tools in estimating mineral and members present in both dust samples and satellite plumes but failed to identify the accurate particle size of the fractions present.

Karimi et al. (2012) compared and evaluated four principal methods of dust source and plume identification using MODIS data. Four MODIS methods were used, including (i) Roskovensky and Liou's dust identification algorithm, (ii) Ackerman's model, (iii) Normalized difference dust index (NDDI), and (iv) Deep Blue algorithm. These techniques were applied to three significant dust events in the Middle East region. In addition, true colour images and the HYSPLIT model were used to evaluate the result of each technique. To optimise the result of dust detection for each technique, the published dust-non-dust thresholds had to be 
considerably adjusted on an event-by-event basis. Results showed that techniques that used brightness temperature (BT) difference were the most reliable techniques for dust source detection in several situations such as multi-plume and multimineralogical conditions (unlike the NDDI index and other optical based algorithms). This weakness impelled them to develop a new model based on Ackerman's technique because of its more precise results in dust source identification. In the newly presented model called Middle East Dust Index (MEDI), $\mathrm{BT}_{29}$ was involved to highlight the difference between dust and desert surfaces as the $\left[\left(\mathrm{BT}_{31}-\mathrm{BT}_{29}\right) /\left(\mathrm{BT}_{32}-\mathrm{BT}_{29}\right)\right]$ equation. In this equation, the values of dusty pixels were $<0.6$, while non-dusty pixels were $>0.6$. Results indicated that the MEDI model was ideal for both identifying dust plume and sources and desert surfaces. Finally, due to some misclassification of the MEDI model in differentiating cirrus clouds from dust plumes, the NDDI index was added to the initial model to distinguish them more accurately.

Shahraiyni et al. (2015) used the well-known methods for monitoring dust storms using MODIS images in arid regions of Middle East utilising a combination of reflective and thermal infrared bands, BTDs and an NDDI method. Upon comparing these three methods, it was demonstrated that the thermal infrared was the best method for the retrieval of the dust storm from MODIS images in the Middle East. Hence, the dust storms were monitored using thermal infrared maps, retrieved from MODIS images.

Li and Song (2009) used two algorithms to extract dust information in China. The formulation formed by band-31 and band-32 (thermal infrared) showed a higher accuracy. This algorithm was built on the difference of brightness temperature when dust existed in air. The dust storm was extracted from other complex objects (Li and Song 2009).

$\mathrm{Xu}$ et al. (2014) built a detailed identification method based on distinct thermal infrared signature of dust. Several dust events that were observed in northern China were analysed, and the usefulness of monitoring the outbreaks of Asian dust was emphasised through the comparison with moderate resolution imaging spectroradiometer (MODIS) visible observations and cloud-aerosol lidar with orthogonal polarisation (CALIOP) data.

Zhang et al. (2006) investigated the possibility of monitoring and quantitatively retrieving dust storm from satellite thermal infrared measurements in China. It was found from satellite observations that for the dust clouds, the observed 11-12 $\mu \mathrm{m}$ brightness temperature difference (BTD) is always negative, while the BTD of $8.5-11 \mu \mathrm{m}$ varies from positive to negative depending on the dust concentration.
Ackerman (1997) investigated the sensitivity of the thermal window region wavelengths to dust among other aerosols and found out that brightness temperature differences between 11 and $12 \mu \mathrm{m}$ were negative during the dust storms. The MODIS cloud mask (Ackerman et al. 2002) has incorporated this simple suspended dust flag for the 11$12 \mu \mathrm{m}$ BTD $<1 \mathrm{~K}$. Following Ackerman's work, Miller (2003) used two different algorithms for dust enhancement. He used reflective properties of spectral ranges of 0.46 and $0.85 \mu \mathrm{m}$ for the enhancement of dust over water and the brightness temperature properties of dust in spectral ranges of 11 and $12 \mu \mathrm{m}$ for desert areas.

The main aim of this research was to employ satellite data for better understanding and monitoring of dust events in the south-west of Iran and over the Persian Gulf and also to find new methods to enhance the dust affected areas and separate them from other features over land and sea. To identify the dusty areas, two different algorithms, namely Mean Normalized Difference Vegetation Index (MNDVI) algorithm and TIR algorithm, were used. In order to investigate the dust events more, other products like MODIS AOD, Dream8b model output, surface observations, etc., were also applied.

The following are the sections of this paper: 2 . Study region (south-west of Iran), 3. Data and method used in this study (Algorithm theoretical basis), 4. Results (Validation analysis), and 5. Discussion and conclusion.

\section{Study region}

The South Asian region is one of the world's most populous and fast-developing regions. Its population of more than 1.7 billion with highly diverse living habits, fast growing industrial and transport sectors, large and increasing demand for power, diverse fuel use for domestic and industrial purposes, and equally diverse geographical features make it a large cauldron of emissions and atmospheric processes. This region is being increasingly recognised to be among the global hotspots of aerosols and anthropogenic trace gases. The complex geography of this region adds a considerable amount of natural aerosols (sea spray, windblown desert dust, pollen, etc.) into the atmosphere (Moorthy et al. 2016). Mashayekhi et al. (2009) showed that dust is the most important aerosol in south-west Asia. Recent studies (Taghavi 2015) have shown that the frequency and intensity of dust events have increased in this area, and that numerical weather models cannot track and detect dust storms correctly. This phenomenon has been insufficiently explored mainly due to the lack of surface 
observations, which are especially sparse in hyper-arid low populated desert regions (Jamalizadeh et al. 2008).

In the past, dust days in this region were more frequent in summer but new surveys show that the frequency of dust has increased in cold season also. Taghavi and Asadi (2008) showed that up until 1970 dust events in south-west Asia used to occur

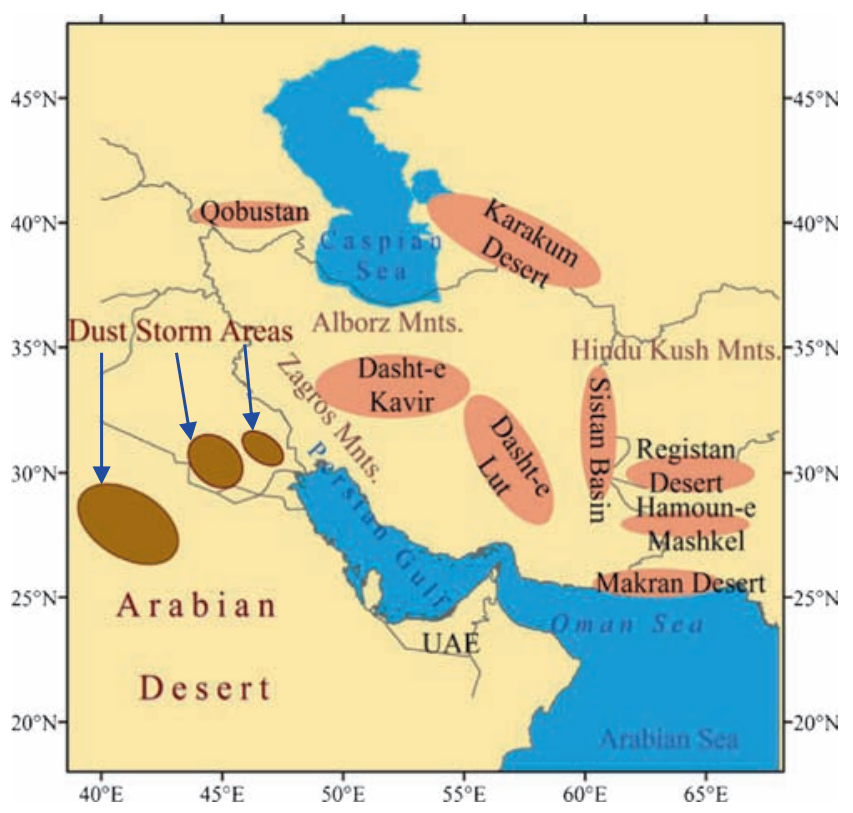

Figure 1. Persian Gulf basin with major surrounding deserts (Alizadeh-Choobari et al. 2015), overlaid on dust sources in south-west Asia, areas of highest dust storm occurrence (shown in dark brown), (COMET 2010). mainly during summer, but recently the region also experiences dust in cold season either.

These storms usually occur when the sub-tropical jet stream migrates northward from the south of the Arabian peninsula and the polar front jet stream moves southward from the European continent. These storms may lead to environmental damage. It should be noted that none of the existing humidity with unstable conditions increases these events (COMET 2010). In south-west Asia, some areas such as the west of Iran are much more prone to dust storms than other lands due to differences in soil and climate. This area is strongly affected by the dust storms blown from the great deserts of Iraq, Saudi Arabia, and Syria every year, especially in the hot season. Even in the bare desert, the sandy areas, such as those found on the Arabian peninsula, generally do not generate dust storms. It is the areas with silt- and clay-rich soils, most common in Iran and Iraq, which are responsible for most dust storms.

Figure 1 shows the important arid and semi-arid areas in the interior of Iran (Alizadeh-Choobari et al. 2015) overlaid on the source regions of dust near the western border of Iran, marked with arrows (COMET 2010). It shows that the highest frequencies occur at the convergence of the common borders between Iran, Iraq, UAE and Saudi Arabia.

Figure 2 shows the distribution of total dust event frequency over Iran derived from 3-h meteorological records of the 20-year period from 1991 to 2010. Five regions of frequent dust events inside Iran were found, which included: (1) the Khuzestan

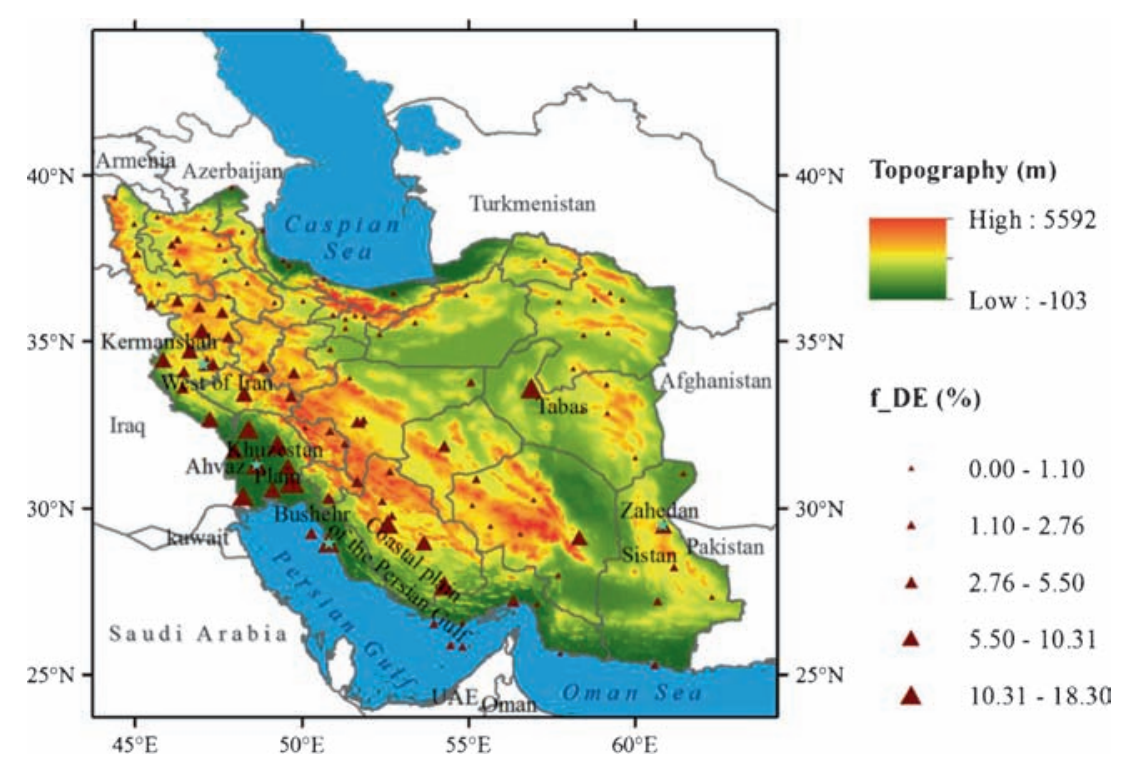

Figure 2. Total dust event frequency (f-DE, triangles) over Iran derived from 3-hr meteorological records of a 20 -yr period from 1991 to 2010 over 111 weather stations. The triangles also show locations of the weather stations across Iran used in the present study. Topographic features of Iran are shown in colours, highlighting the Alborz Mountains in northern Iran and the Zagros Mountains extend from north-west to south of Iran. Five regions of frequent dust events, as well as surrounding countries and seas, are depicted in the figure (Alizadeh-Choobari et al. 2015). 
Plain in south-western Iran over the northern tip of the Persian Gulf; (2) Iran's coastal plain of the Persian Gulf; (3) west of Iran; (4) Tabas in eastcentral of Iran; and (5) Sistan in east to south-east of Iran (Alizadeh-Choobari et al. 2015).

\section{Data and methodology}

\subsection{Algorithm physical basis}

Due to specific optical properties of dust particles, satellite observed radiances carry the spectral signatures of dust particles that are different from molecular, cloud, and the underlying surface. Based on these differences, various detection schemes have been developed to distinguish dust. In practice, detections are based on the analysis of reflectance (or radiance) in visible bands or $\mathrm{BT}$ in IR bands. Inferring the signature of dust can use the magnitude of the differences of BTs in selected bands (or channels). It is the essence of aerosol detection algorithms (Zhao et al. 2010).

Brightness temperature is a descriptive measure of radiation in terms of the temperature of a hypothetical blackbody emitting an identical amount of radiation at the same wavelength (NASA GES DISC 2017).

For a black body, Planck's law gives

$$
B_{\lambda}(T)=\frac{2 h c^{2}}{\lambda^{5}\left[\exp \left(\frac{c h}{k \lambda t}\right)-1\right]},
$$

where $B_{\lambda}$ is the black body's irradiance, $T$ is the temperature of the black body, $h$ is Planck's constant, $c$ is the speed of light; and $k$ is Boltzmann's constant. This equation is used to find the brightness temperatures from radiances of the satellite sensors like MODIS.

For a grey body, the spectral radiance is a portion of the black body radiance, determined by the emissivity $\varepsilon$. That makes the reciprocal of the brightness temperature

$$
T=\frac{h c}{\lambda_{i} k \ln \left(\frac{2 h c^{2}}{L\left(\lambda_{i}\right) \lambda_{i}^{5}}+1\right)} .
$$

The BTD between 11 and $12 \mu \mathrm{m}$ has been widely used to differentiate dust from other aerosols and cloud. The use of BTD $[11,12]$ to discriminate dust cloud from meteorological clouds is called the 'IR split windows' technique. It is found that, no matter what the surface temperatures are, the absolute value of negative BTD $[11,12]$ always increases with the lower surface visibility (meaning more dust) when the visibility is higher than $500 \mathrm{~m}$, but the relation trend of the absolute $\operatorname{BTD}[11,12]$ reverses at the point when the surface visibility becomes very poor. This kind of feature for SDS (sand and dust storm) is found from the actual image observed by the satellite. In addition, BTD $[11,12]$ in the thermal split window channels depends on the density of airborne dust.

The essential principle of TIR method was built on the following fact: when there are no aerosols along the atmospheric path of observation, the BTs at $8.5,11$, and $12 \mu \mathrm{m}$ are determined by the surface temperature $T_{s}$ and surface emissivity $\varepsilon$; when aerosols exist, they can impact the brightness temperatures at these three channels. For many types of aerosols, the refractive indices generally show different and remarkable spectral variances within an $8-13 \mu \mathrm{m}$ spectrum, causing different relative changing trends of BTs received by satellite sensors at these three channels after the radiation goes through the aerosol-loaded atmospheric path (Guang-Yu and Yuan-Long 2010).

Furthermore, in order to get better identification of the dust, two different colour compositions of MODIS bands are applied. Figure 3( $a$ and $b$ ) shows a dust case that colour composition technique is applied. Results show that this method could not detect the dust area clearly. Hence, enhancement by algorithms must be applied.

\subsection{Data and methods}

MODIS sensor measures radiation in 36 narrow spectral bands situated between 0.4 and $14.4 \mu \mathrm{m}$. All infrared channels are available at $1 \mathrm{~km}$ subsatellite resolution, with a subset of visible and shortwave infrared channels at native resolutions of either $500 \mathrm{~m}$ ( 5 channels) or $250 \mathrm{~m}$ (2 channels). In sun-synchronous orbits, Terra and Aqua provide 10:30 and 13:30 local equatorial crossing times, respectively (Miller 2003). The format of these files is the widely used Hierarchical Data Format (HDF) (MODIS Level 1B Product User's Guide 2009).

In the present study, enhancement of four dust events that occurred in the west of Iran on 9th June 2009, 20th May 2010, 4th March 2011 and 13th April 2011 are performed. In order to do so, seven MODIS bands, i.e., band 1, 2, 3, 4, 29, 31 and 32 are selected for dust enhancement and analysis. The spectral ranges of these bands are listed in table 1 .

Dust enhancement is based on the BTDs in two or three channels and MNDVI using two different algorithms named as MNDVI algorithm and TIR algorithm. The MODIS HDF data of four dust storm cases that occurred in the west of Iran are selected as examples for testing and developing the enhancement algorithms. The algorithms are written using ENVI (Environment for Visualizing Images) software, and output products are in HDF format. 

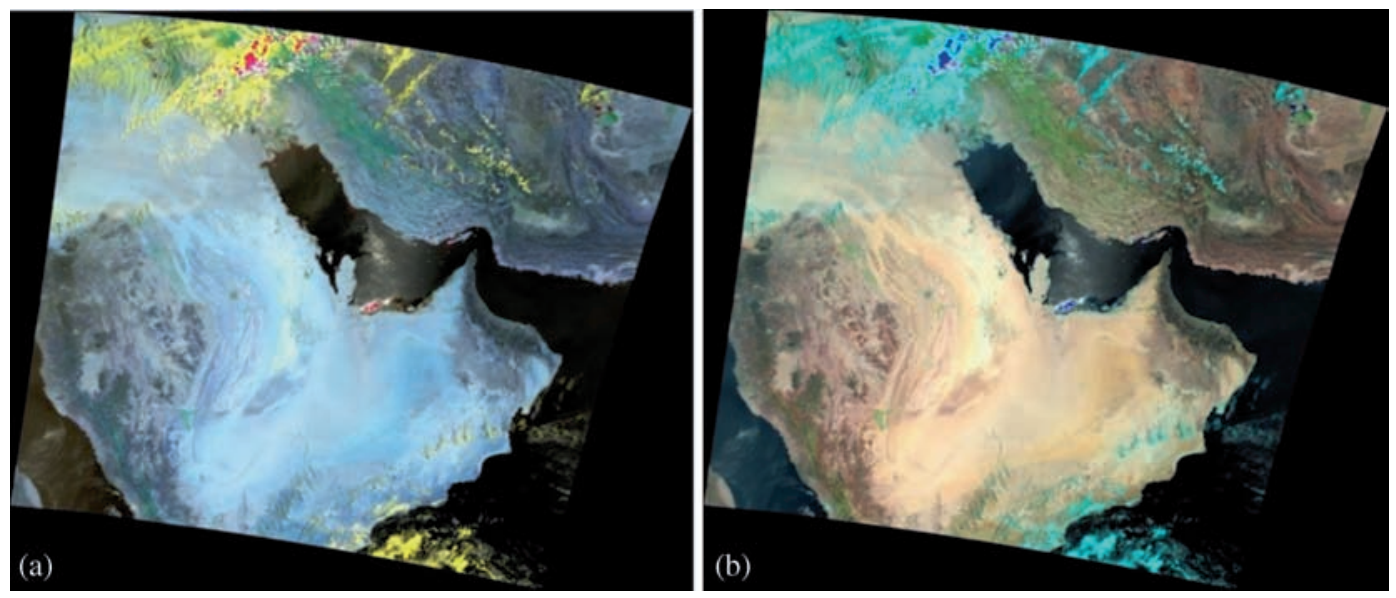

Figure 3. Two different MODIS RGB colour compositions to detect dust in case of 20th May 2010 in the south-west of Iran. Composition of (a) Bands 1, 2, and 6, and (b) Bands: 7, 2, and 1.

Table 1. Characteristics of bands used in this study (MODIS website 2009).

\begin{tabular}{|c|c|c|c|c|}
\hline Primary use & Band & Bandwidth & $\begin{array}{l}\text { Spectral radiance } \\
\left(\mathrm{W} / \mathrm{m}^{2}-\mu \mathrm{m}-\mathrm{sr}\right)\end{array}$ & $\begin{array}{cl} & \text { Required } \\
\mathrm{SNR}^{1} \text { or } \mathrm{NE}[\Delta] \mathrm{T}(\mathrm{K})^{2}\end{array}$ \\
\hline \multirow[t]{2}{*}{ Land/cloud/aerosols boundaries } & 1 & $620-670 \mathrm{~nm}$ & 21.8 & 128 \\
\hline & 2 & $841-876 \mathrm{~nm}$ & 24.7 & 201 \\
\hline \multirow[t]{2}{*}{ Land/cloud/arosols properties } & 3 & $459-479 \mathrm{~nm}$ & 35.3 & 243 \\
\hline & 4 & $545-565 \mathrm{~nm}$ & 29.0 & 228 \\
\hline Surface/cloud temperature & 20 & $3.660-3.840 \mu \mathrm{m}$ & $0.45(300 \mathrm{~K})$ & 0.05 \\
\hline Cloud properties & 29 & $8.400-8.700 \mu \mathrm{m}$ & $9.58(300 \mathrm{~K})$ & 0.05 \\
\hline Surface/cloud & 31 & $10.780-11.280 \mu \mathrm{m}$ & $9.55(300 \mathrm{~K})$ & 0.05 \\
\hline Temperature & 32 & $11.770-12.270 \mu \mathrm{m}$ & $8.94(300 \mathrm{~K})$ & 0.05 \\
\hline
\end{tabular}

${ }^{1}$ Signal-to-noise ratio.

${ }^{2}$ Noise-equivalent temperature difference.

MNDVI algorithm: In first algorithm (MNDVI), Normalized Difference Vegetation Index (NDVI), MNDVI indices and BTD $[11,12]$ parameter are used to separate the semi-arid areas with low vegetation cover and the threshold temperature of $290 \mathrm{~K}$ in MODIS band-31 is used to distinguish cloud from dust phenomena. The definition of NDVI is as follows:

$$
\mathrm{NDVI}=\frac{\left(\mathrm{R}_{0.86 \mu \mathrm{m}}-\mathrm{R}_{0.64 \mu \mathrm{m}}\right)}{\left(\mathrm{R}_{0.86 \mu \mathrm{m}}+\mathrm{R}_{0.64 \mu \mathrm{m}}\right)},
$$

where $R_{0.64 \mu \mathrm{m}}$ and $\mathrm{R}_{0.86 \mu \mathrm{m}}$ are the reflectances of MODIS band-1 and band-2, respectively.

Clouds are spectrally neutral and appear white to our eyes. For this reason, the reflectance at 0.86 , 0.64 and $0.47 \mu \mathrm{m}$ have been used to identify dust (Zhao et al. 2010). To get better results, MNDVI index smaller than a threshold is used (equation 4), that is obtained by trial-and-error in different dust cases in this area.

$$
\mathrm{MNDVI}=\frac{(\mathrm{NDVI})^{2}}{\left(\mathrm{R}_{0.64 \mu \mathrm{m}}\right)^{2}} .
$$

The MNDVIs smaller than 0.08 (equation 5) is added to identify dust over some semi-arid surfaces with small amounts of vegetation. This is because dust absorbs at blue wavelengths and appears visually to be brownish in colour.

$$
\text { MNDVI }<0.08 \text {. }
$$

After converting the radiances to brightness temperatures with equation (2), to eliminate the clouds from dust area equation (6) is applied:

$$
\mathrm{BT}_{11 \mu \mathrm{m}} \geq 290 \mathrm{~K},
$$

where $\mathrm{BT}_{11 \mu \mathrm{m}}$ is the brightness temperature of MODIS band-31. This threshold could be changed according to region and season. For decreasing the surface effects equation (7) is applied:

$$
\left(\mathrm{BT}_{11 \mu \mathrm{m}}-\mathrm{BT}_{12 \mu \mathrm{m}}\right)<0,
$$

where BTD $[11,12]$ defines the 11-12 $\mu \mathrm{m}$ brightness temperature difference. The magnitude of negative BTD $[11,12]$ is driven by: (a) the thickness of the dust layer (temperature), (b) the mass per area of dust cloud (concentration), (c) the composition of airborne dust (refractive index), and (d) the size 
of the dust particles (size distribution) (Zhang et al. 2006). So, positive BTD $[11,12]$ values are associated with clear-sky atmospheres. In addition, dust has a larger absorption at $12 \mu \mathrm{m}$ than at $11 \mu \mathrm{m}$, so that dust plumes generally have a higher emissivity and lower transmissivity in the $12 \mu \mathrm{m}$ channel (Ackerman 1997; Dunion and Velden 2004). Actually, dust absorbs more radiation at $12 \mu \mathrm{m}$ than $11 \mu \mathrm{m}$, which causes the brightness temperature difference between the two bands to become negative. Moreover, there is absorption and emission of water vapour in the 11 and $12 \mu \mathrm{m}$ channels (Zhao et al. 2010). When the dust layer is optically thick, the dust particles cause a negative brightness temperature difference.

TIR algorithm: The second (TIR) algorithm, called thermal infrared algorithm is based on the optical and radiative physical properties of dust in mid-infrared and thermal infrared spectral regions, which include the BTD in split window channels.
For second algorithm $\left(\mathrm{BT}_{8.5 \mu \mathrm{m}}-\mathrm{BT}_{11 \mu \mathrm{m}}\right)-\left(\mathrm{BT}_{11 \mu \mathrm{m}}-\right.$ $\mathrm{BT}_{12 \mu \mathrm{m}}$ ), values greater than a threshold (equation 8), $\left(\mathrm{BT}_{11 \mu \mathrm{m}}-\mathrm{BT}_{12 \mu \mathrm{m}}\right)$ values lower than zero (equation 7 ) and a threshold temperature of $290 \mathrm{~K}$ in MODIS band-31 to eliminate the clouds are considered.

Thus, with increasing amounts of dust, the difference $\left(\mathrm{BT}_{8.5 \mu \mathrm{m}}-\mathrm{BT}_{11 \mu \mathrm{m}}\right)$ is increased and the $\left(\mathrm{BT}_{11 \mu \mathrm{m}}-\mathrm{BT}_{12 \mu \mathrm{m}}\right)$ is decreased.

$$
\left(\mathrm{BT}_{8.5 \mu \mathrm{m}}-\mathrm{BT}_{11 \mu \mathrm{m}}\right)-\left(\mathrm{BT}_{11 \mu \mathrm{m}}-\mathrm{BT}_{12 \mu \mathrm{m}}\right)>-1 .
$$

Finally, equations (6) and (7) are applied to the second algorithm too.

To get the thresholds for a MODIS granule with dust plume over Iran, an area of dust, in the region was defined by the red rectangle (figure 4a) So, to drive the thresholds, a scatter plot is made (figure $4 \mathrm{~b}$ ). As shown in figure 4(a and b), BTD (31-32) for a dusty rectangle is almost negative but BTD (20-31)
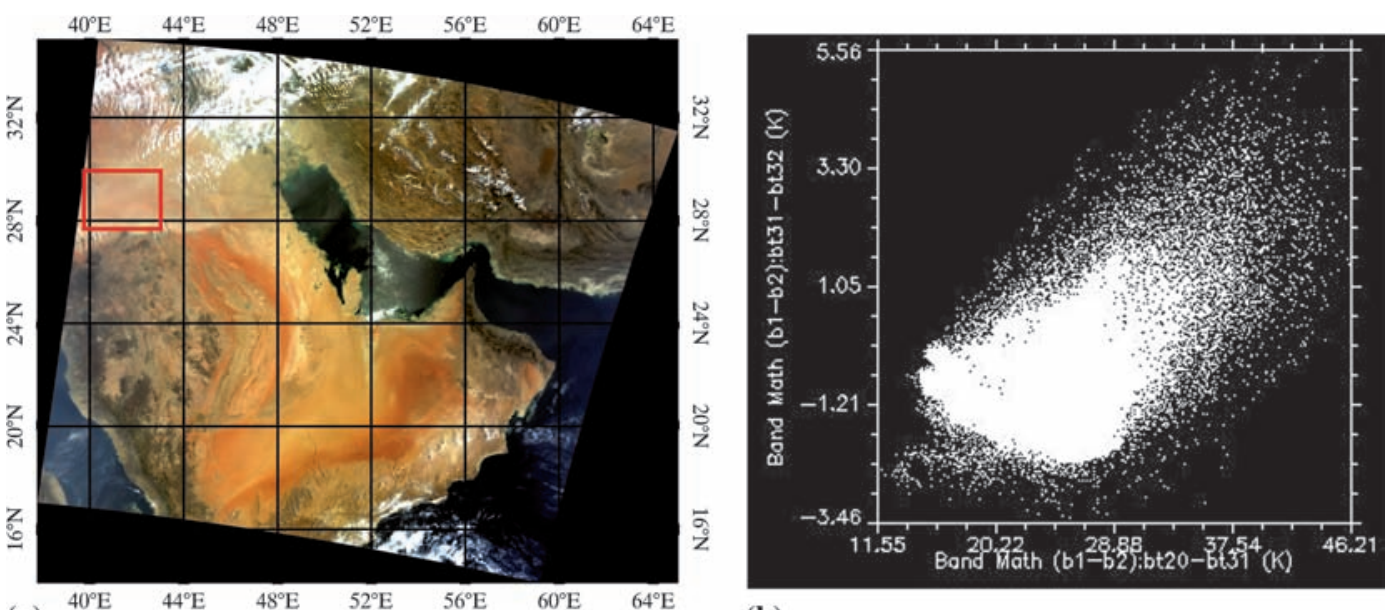

(b)

Figure 4. (a) RGB MODIS image, dusty rectangle shown in red, (b) scatter plot of BTD (31-32) vs. BTD (20-31) bands for 20th May 2010, 07:20 UTC Terra satellite.

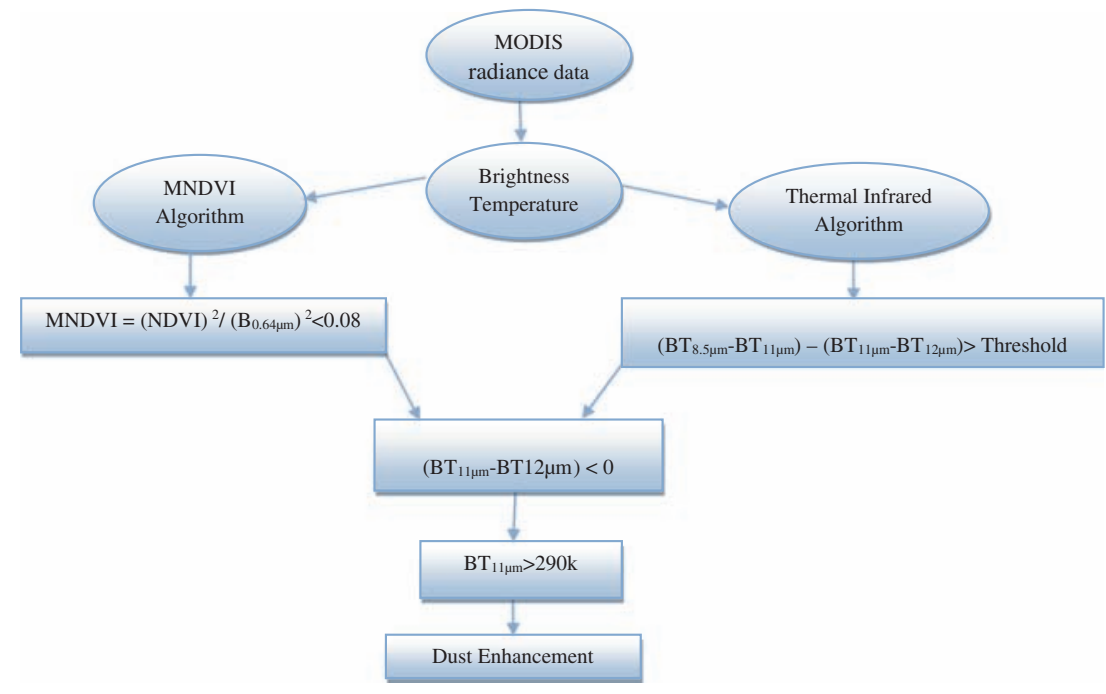

Figure 5. Dust enhancement flowchart. 

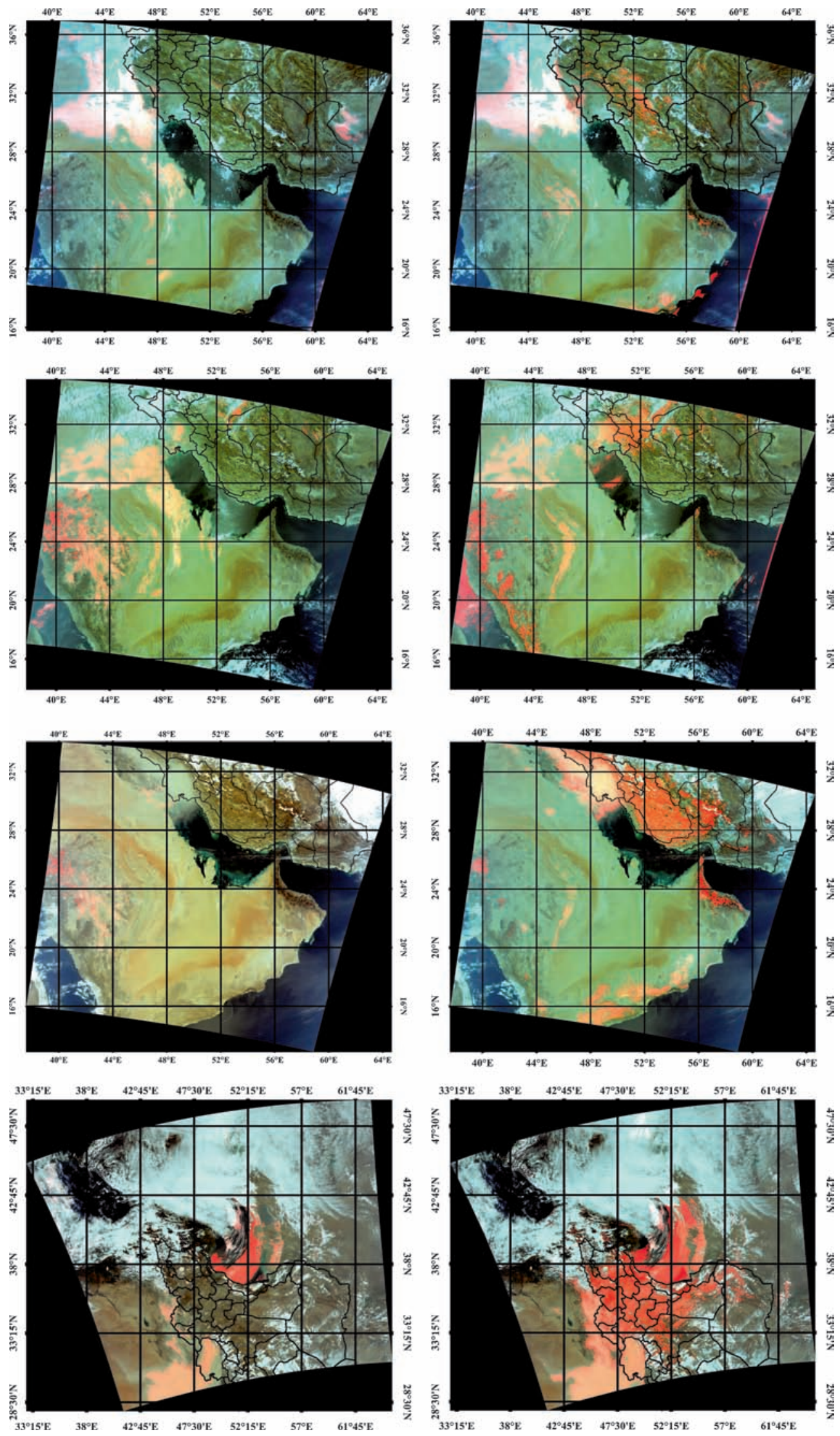

Figure 6. Enhancement of dust events using (left) MNDVI and (right) TIR method for four dust cases. 
is positive, depending on the intensity of dust. This is another way to indicate the thresholds for detecting dusty regions. Figure 5 shows the flowchart applied for enhancing the dusty areas.

\section{Results}

To enhance the dusty areas with true colour images, a reflectance combination of bands 1, 3 and 4 of MODIS is used. So the dusty regions are shown in pink colour (figure 6). As seen in this figure, the first algorithm had many missed dusty areas, and MNDVI index surveys show that this index cannot clearly detect the dust. Therefore, the algorithm of combining brightness temperature difference of dust between the wavelengths of $8.5 \mu \mathrm{m}$ (MODIS band-29) and $11 \mu \mathrm{m}$ (MODIS band-31) with negative values of bands 31 and 32 brightness temperature differences were used. To define dust areas $\left(\mathrm{BT}_{8.5 \mu \mathrm{m}}-\mathrm{BT}_{11 \mu \mathrm{m}}\right)-\left(\mathrm{BT}_{11 \mu \mathrm{m}}-\mathrm{BT}_{12 \mu \mathrm{m}}\right)$ values larger than the obtained threshold and $\left(\mathrm{BT}_{11 \mu \mathrm{m}}-\mathrm{BT}_{12 \mu \mathrm{m}}\right)$ values smaller than zero are applied. Results show that dust area is obviously better enhanced in the second algorithm.

\subsection{MODIS AOD}

Regional distribution of aerosols, their interannual variabilities, and the spectral optical depths are essential inputs to regional and global aerosol models to assess regional radiative forcing and climatic impacts (Saha et al. 2005). Aerosols not only perturb the radiative energy balance by interacting with solar and terrestrial radiation but also by changing cloud properties and lifetime (Hsu et al. 2013). In spite of these facts, still aerosols indirect and semi-direct radiative effects are known with significantly large uncertainty (Lohmann and Feichter 2005; Stevens and Feingold 2009).

The aerosol optical depth (AOD or $\tau$; also called aerosol optical thickness or AOT) refers to the optical loading of the aerosols or a measure of radiation extinction at the encounter of aerosol particles in the atmospheric column. It is most closely related to the total surface area of the aerosol. AOD is spectrally dependent, meaning it varies by wavelength. MODIS ocean AOD are reported in seven wavelengths: $0.47,0.55,0.65,0.86,1.2,1.6$ and $2.1 \mu \mathrm{m}$. AOD is a unitless value. There are two separate and distinct 'Dark Target' (DT) algorithms for retrieving AOD. The first one is used for retrieving aerosol information over oceans (dark in visible and longer wavelengths) and the second one over vegetated/dark-soiled land (dark in the visible). In theory, these algorithms can be applied to any sensor that measures reflectance in appropriate wavelength bands covering visible (VIS), near-IR (NIR) and shortwave-IR (SWIR). But, these were originally developed for use with MODIS data (NASA, Dark target 2016).

Currently, global MODIS aerosol retrievals over land are performed with the main Dark Target algorithm complimented with the Deep Blue Algorithm over bright deserts. The Dark Target algorithm relies on surface parameterization, which relates reflectance in MODIS visible bands with the $2.1 \mu \mathrm{m}$ region, whereas the Deep Blue algorithm uses an ancillary angular distribution model of surface reflectance developed from the time series of clear-sky used MODIS observations (Lyapustin et al. 2010).

The MODIS aerosol products are used to study aerosol climatology, sources and sinks of specific aerosol types (e.g., sulphates and biomass-burning aerosol), the interaction of aerosols with clouds, and atmospheric corrections of remotely sensed surface reflectance over land and ocean. The wavelength of 550 nanometers is widely used for retrieving the AODs because at this wavelength we can eliminate the surface radiances, so what is received at the sensors is the influence of pollutants and dust particles on the atmosphere. Detailed information about MODIS AOD (Dark target) data used here is given in table 2. Here, MODIS Giovanni Terra and Aqua level 3 data (http://giovanni. sci.gsfc.nasa.gov/giovanni/) are used to retrieve the AODs.

\subsection{BSC-DREAM8b model}

Dust models have been applied to the prediction of Asian dust storms with considerable success. Several research groups have reported that their dust models can correctly predict the spatial pattern

Table 2. Data summary for MODIS AOD (MODIS Daily Level 3 Giovanni Snapshot ${ }^{1}$ ).

\begin{tabular}{|c|c|c|c|c|}
\hline Dataset & Coverage & Availability & $\begin{array}{l}\text { Spatial } \\
\text { resolution }\end{array}$ & $\begin{array}{l}\text { Temporal } \\
\text { resolution }\end{array}$ \\
\hline $\begin{array}{l}\text { MODIS Terra Collection005 Level-3 } \\
\text { atmosphere global daily product, MOD08_D3 }\end{array}$ & Global & 02/24/2000-Present & $1^{\circ} \times 1^{\circ}$ & Daily \\
\hline $\begin{array}{l}\text { MODIS Aqua Collection005 Level-3 atmosphere } \\
\text { global daily product, MYD08_D3 }\end{array}$ & Global & 07/03/2002-Present & $1^{\circ} \times 1^{\circ}$ & Daily \\
\hline
\end{tabular}

${ }^{1}$ http://disc.sci.gsfc.nasa.gov/giovanni/modis_daily_level3_snapshot.shtm 
and temporal evolution of Asian dust storms, as well as the order of magnitude of dust concentration, emission and deposition. Land-surface data are required for the atmospheric model as well as for land-surface, dust-emission and dust-deposition schemes. The key land-surface data required for dust modelling include: (1) soil particle-size distribution; (2) soil surface characteristics; (3) vegetation coverage; (4) vegetation leaf-area index and roughness frontal area index (Shao and Dong 2006).

The Earth Sciences Department of Barcelona Supercomputing Center (BSC) maintains dust forecast operations with the Dust Regional Atmospheric Model and conducts modelling research and developments for short-term prediction. The model predicts the atmospheric life cycle of the eroded desert dust that develops as a pluggable component of the Eta/NCEP (National Centers for Environmental Prediction) model. It solves the Euler-type partial differential non-linear equation for dust mass continuity and it fully inserts as one of the governing prognosis equations in the atmospheric Eta/NCEP atmospheric model equations. In the DREAM system, a dust cycle simulation module, which coupled online with the National Centers for Environmental Prediction (NCEP) operational Eta Model (Janjic 1984), simulates dust production, dust advection and turbulent diffusion, and dry and wet deposition (Shao et al. 1993; Nickovic et al. 2001). Horizontally, the model uses semi-staggering Arakawa E grid (Arakawa and Lamb 1977). Vertically, it uses a step-mountain representation (Mesinger et al. 1988).

The available modelled data consists in diagnostic simulations of the BSC-DREAM8b (v1.0 and v2.0), and NMMB/BSC-Dust over northern Africa, the Mediterranean and the Middle East. The simulated dust distributions consist of daily runs in 24-hr daily forecasts. The meteorological fields are initialized every $24 \mathrm{hr}$ (at 0 UTC) and boundary conditions are updated every $6 \mathrm{hr}$ with the NCEP/FNL final operational global analysis data $\left(1^{\circ} \times 1^{\circ}\right)$. Since there are no satisfactory threedimensional dust concentration observations yet, the initial state of dust concentration in the model is defined by the $24-\mathrm{hr}$ forecast from the previousday model run. The model at the starting day is run using 'cold start' conditions, i.e., the zeroconcentration initial state. These long-term series do not correspond with the daily dust forecast shown in the BSC website. They have been rerun in order to provide to the users long-term homogeneous simulations for their purposes (BSC 2016).

The main general features of the original DREAM model (Nickovic et al. 2001) are:

- Dust production scheme (Shao et al. 1993) with introduced viscous sub-layer (Janjić 1994).
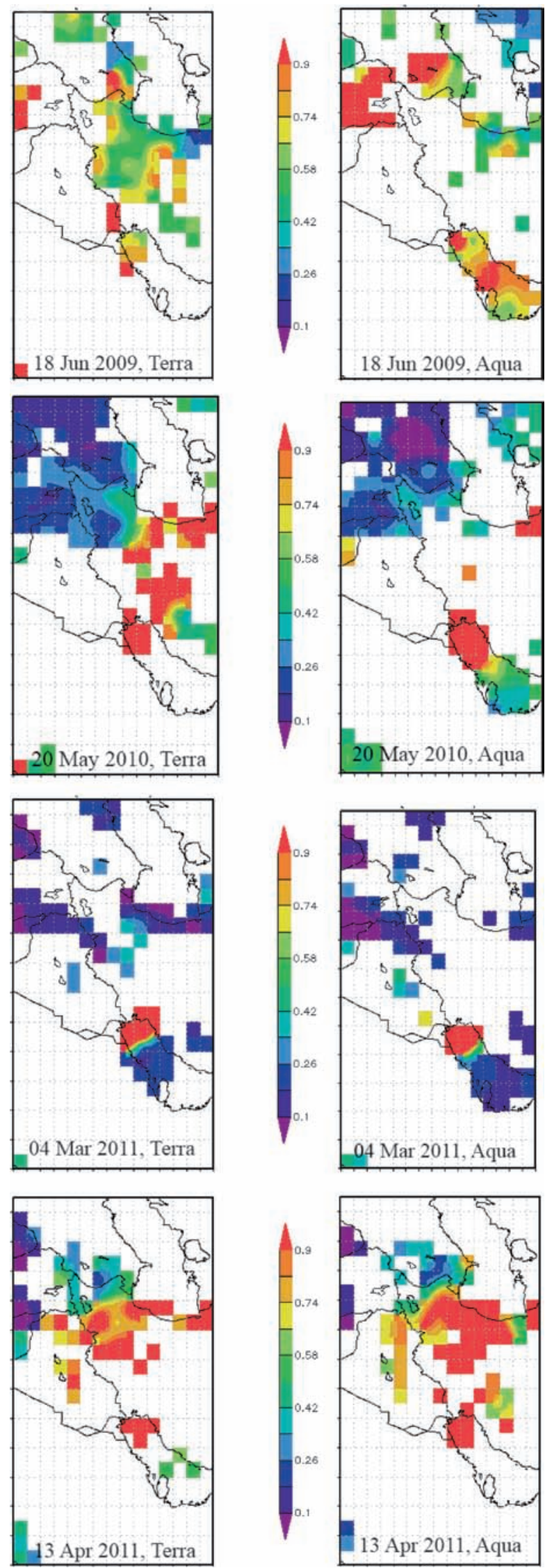

Figure 7. MODIS AOD retrievals in four dust cases, at $550 \mathrm{~nm}$ from two satellites: (left) Terra (7:20 UTC) and (right) Aqua (9:45 UTC). 
- Soil wetness effects on dust production (Fecan et al. 1998).

- Dry deposition (Giorgi 1986) and below cloud scavenging.

- Horizontal and vertical advection, turbulent and lateral diffusion (Janjic 1994) represented as for other scalars in the Eta/NCEP model.

\subsection{Result analysis and validation}

The results were compared with MODIS AOD retrievals at $550 \mathrm{~nm}$ from Terra and Aqua satellites (figure 7). As seen in MODIS AOD retrievals in dust case, 18th June 2009, the AODs are almost high in some parts of the north of Persian Gulf, but in other areas enhanced by TIR algorithm (figure 6), e.g., the north-west of the Persian Gulf and over Iraq, there is no AOD data to compare. Fourth March, 2011, AODs are up to 0.9 over north of Persian Gulf, but 20th May 2010, AODs are high at almost west half of Iran and even over the Caspian Sea, there is also the same situation on 13th April 2011, that AODs are high even over the Caspian Sea where the dust has been transported. It seems that in some areas the AODs are missed in MODIS AOD retrievals. Therefore enhancement by algorithms is essential. For this study, AOD outputs of DREAM-8b model in $550 \mathrm{~nm}$ are used to see how it works when compared with other results. The results are given in figure 8 . There are differences in the amount of AODs estimated by DREAM-8b model and MODIS AOD retrievals.

There are many kinds of surface observations for weather and special observation for SDS. Validation using the ground-based synoptic observations for SDS monitoring is made here from the IRIMO (Iranian Meteorological Organization) weather station data for the city of Ahvaz in the south-west of Iran located at the latitude and longitude of 31.31 and 48.68 degrees, respectively (table 3 ). The time difference between MODIS data and in-situ observations are $<10 \mathrm{~min}$. These are the data records at some intense hours of dust situation in this station. The visual visibility at each site is reported every $30 \mathrm{~min}$. As seen in these reports none existing of enough humidity (large differences between temperature and dew point) could cause intense dust cases with low visibilities. Sunphotometer measurements of the direct (collimated) solar radiation provide information to calculate the columnar AOD. Two data versions (versions 1 and 2) and three quality levels (levels 1.0, 1.5, 2.0) exist for each product (Aeronet (Aerosol Robotic Network) 2016). Comparison with in-situ observations collected by sunphotometers in three stations of Kuwait University, Solar Village and Zanjan, at level 1.5 are shown in figure 9 ; as seen in these time series, the aerosol optical thickness has reached one
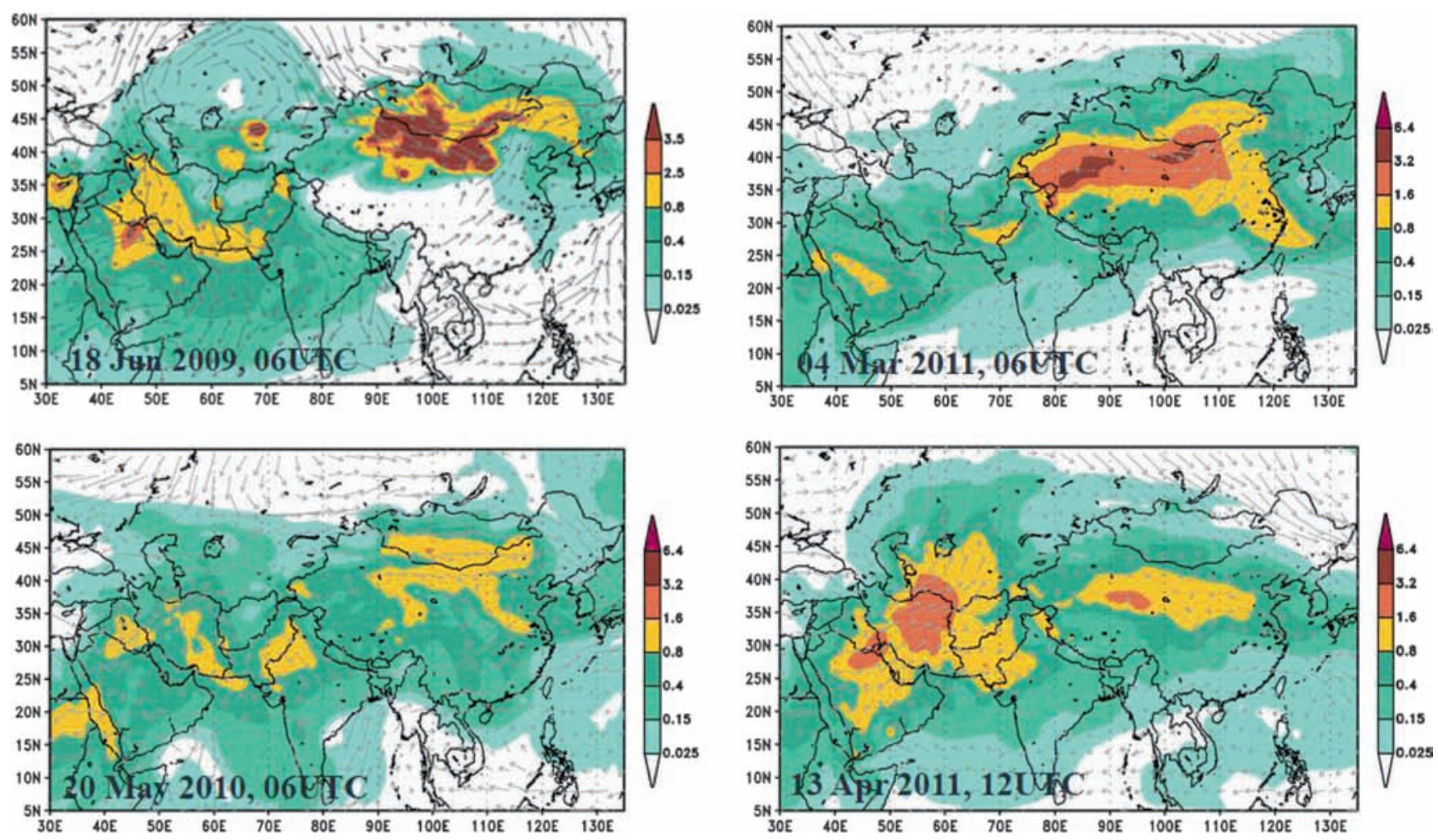

Figure 8. BSC-DREAM8b Model outputs of AOD in $550 \mathrm{~nm}$. 
Table 3. Weather report from IRIMO for Ahwaz synoptic station.

\begin{tabular}{|c|c|c|c|c|c|c|}
\hline Date and local time & Weather & $\begin{array}{c}\mathrm{T} \\
\left({ }^{\circ} \mathrm{C}\right)\end{array}$ & $\begin{array}{l}\mathrm{DP} \\
\left({ }^{\circ} \mathrm{C}\right)\end{array}$ & $\begin{array}{l}\text { Visibility } \\
\quad(\mathrm{m})\end{array}$ & $\begin{array}{l}\text { Pressure } \\
(\mathrm{hPa})\end{array}$ & $\begin{array}{l}\text { Wind speed and } \\
\text { direction }\end{array}$ \\
\hline 18 June, 2009, 13:30 & 6 & 44 & 9 & 5000 & 1000 & $\begin{array}{c}\mathrm{S} \\
9 \mathrm{mps}, 32.4 \mathrm{~km} / \mathrm{hr}\end{array}$ \\
\hline 18 June, 2009, 14:30 & 6 & 44 & 7 & 4000 & 1000 & $\begin{array}{c}\mathrm{SW} \\
6 \mathrm{mps}, 21.6 \mathrm{~km} / \mathrm{hr}\end{array}$ \\
\hline 20 May, 2010, 12:00 & inte & 38 & 17 & 1500 & 1005 & $\begin{array}{c}\mathrm{W} \\
1 \mathrm{mps}, 3.6 \mathrm{~km} / \mathrm{hr}\end{array}$ \\
\hline 20 May, 2010, 12:30 & 19 & 40 & 14 & 1500 & 1005 & $\begin{array}{c}\mathrm{W} \\
3 \mathrm{mps}, 10.8 \mathrm{~km} / \mathrm{hr}\end{array}$ \\
\hline 4 March, 2011, 12:00 & an: & 18 & -2 & 800 & - & $\left\{\begin{array}{c}\mathrm{W} \\
2 \mathrm{mps}, 7.2 \mathrm{~km} / \mathrm{hr}\end{array}\right.$ \\
\hline 4 March, 2011, 12:30 & ficis: & 19 & -4 & 800 & - & $\left\{\begin{array}{c}\mathrm{SW} \\
2 \mathrm{mps}, 7.2 \mathrm{~km} / \mathrm{hr}\end{array}\right.$ \\
\hline 13 April, 2011, 14:00 & 6 & 24 & -6 & 300 & - & $\begin{array}{c}\mathrm{NW} \\
6 \mathrm{mps}, 21.6 \mathrm{~km} / \mathrm{hr}\end{array}$ \\
\hline 13 April, 2011, 14:30 & 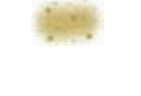 & 24 & -7 & 300 & - & $\begin{array}{c}\mathrm{W} \\
5 \mathrm{mps}, 18 \mathrm{~km} / \mathrm{hr}\end{array}$ \\
\hline
\end{tabular}
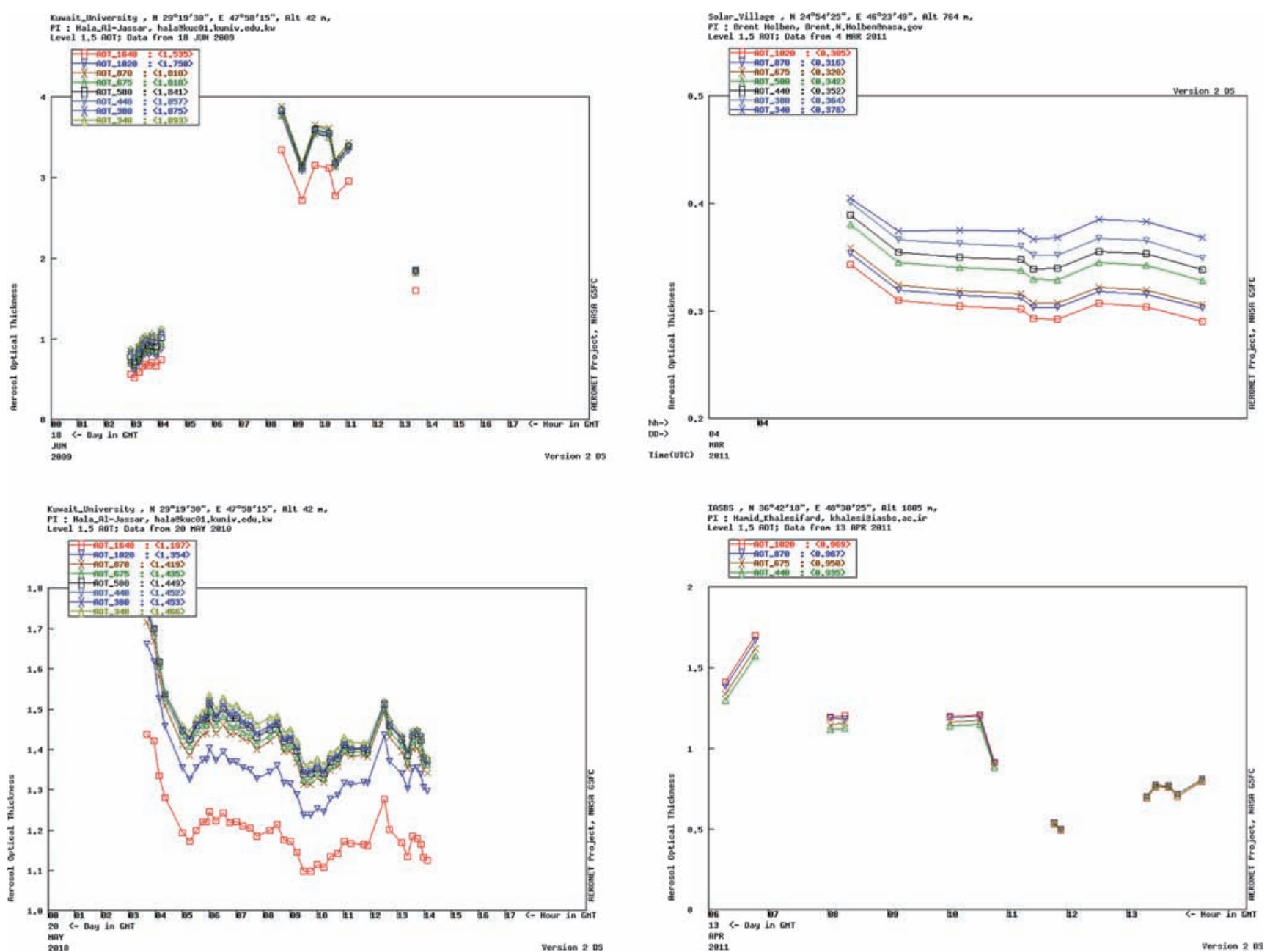

Figure 9. Aerosol optical thickness from in-situ sunphotometers, time series data (Kuwait University, Zanjan and Solar village stations). 

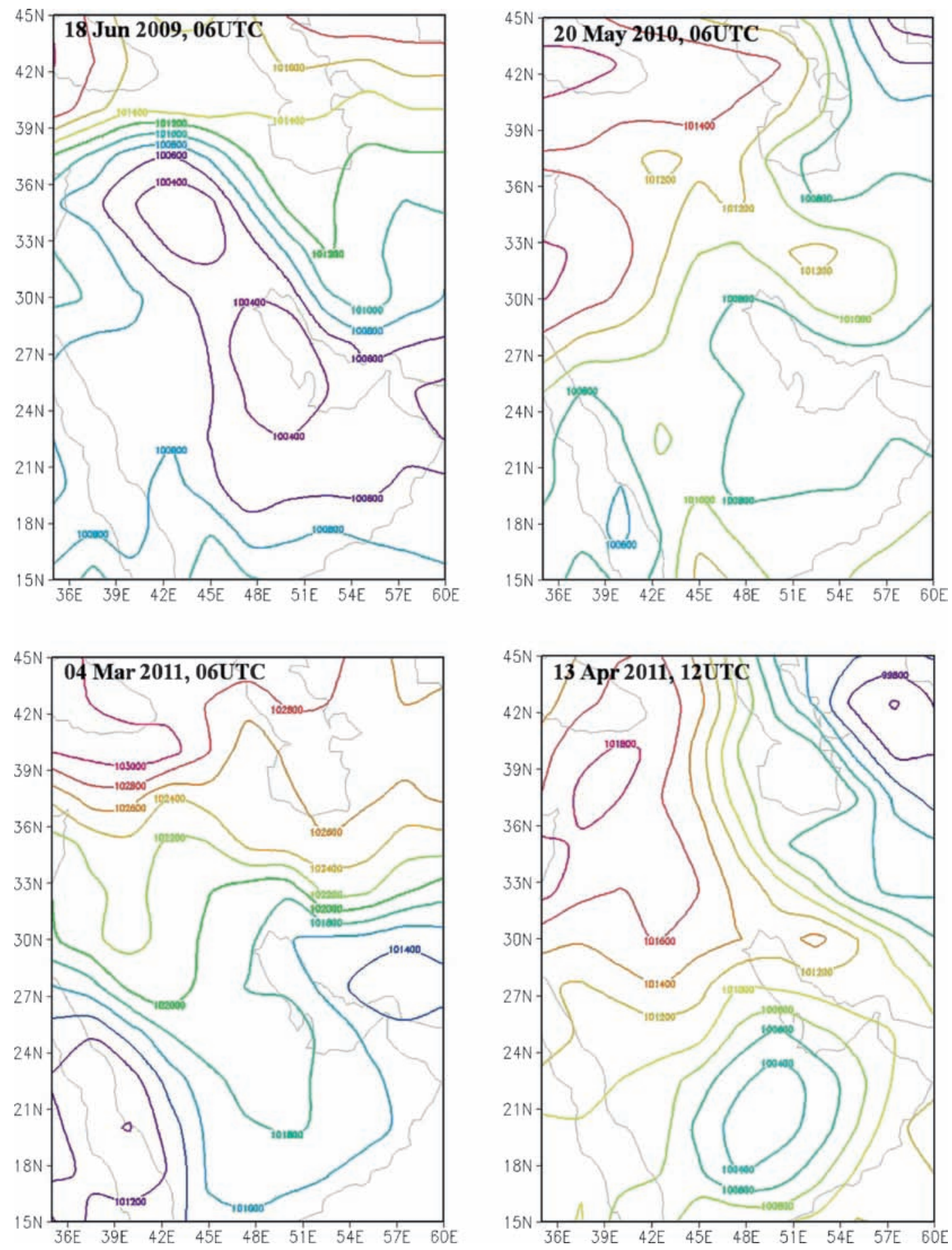

Figure 10. Sea level pressure from NCEP/NCAR reanalysis data.

of its maximums at around 07 UTC for Kuwait university station in case 18th June 2009. The problem here is that there are not enough sunphotometer stations to cover the whole area affected by dust. In addition, as this instrument works with the sunlight, when there is an intense dust storm in the region, the sunphotometer data will be affected and the results will not have enough accuracy. This will also confirm the need for remote sensing data with fine spatial coverage like MODIS radiance and reflectance data.
Sea level pressure maps from NCEP/NCAR Reanalysis2 data are used to see the synoptic weather situation in these dust cases (figure 10). It was found out that in all cases there was a low pressure in the south-west of Iran and over Arabian peninsula and Red Sea. On sea surface pressure plots in case 20th May 2010, a very strong low pressure was recognised in the south-west of Iran and over Arabian peninsula; with a centre of $1006 \mathrm{mb}$. But in the case of 4th March 2011, a weaker low pressure with a centre of $1010 \mathrm{mb}$ was recognised. 

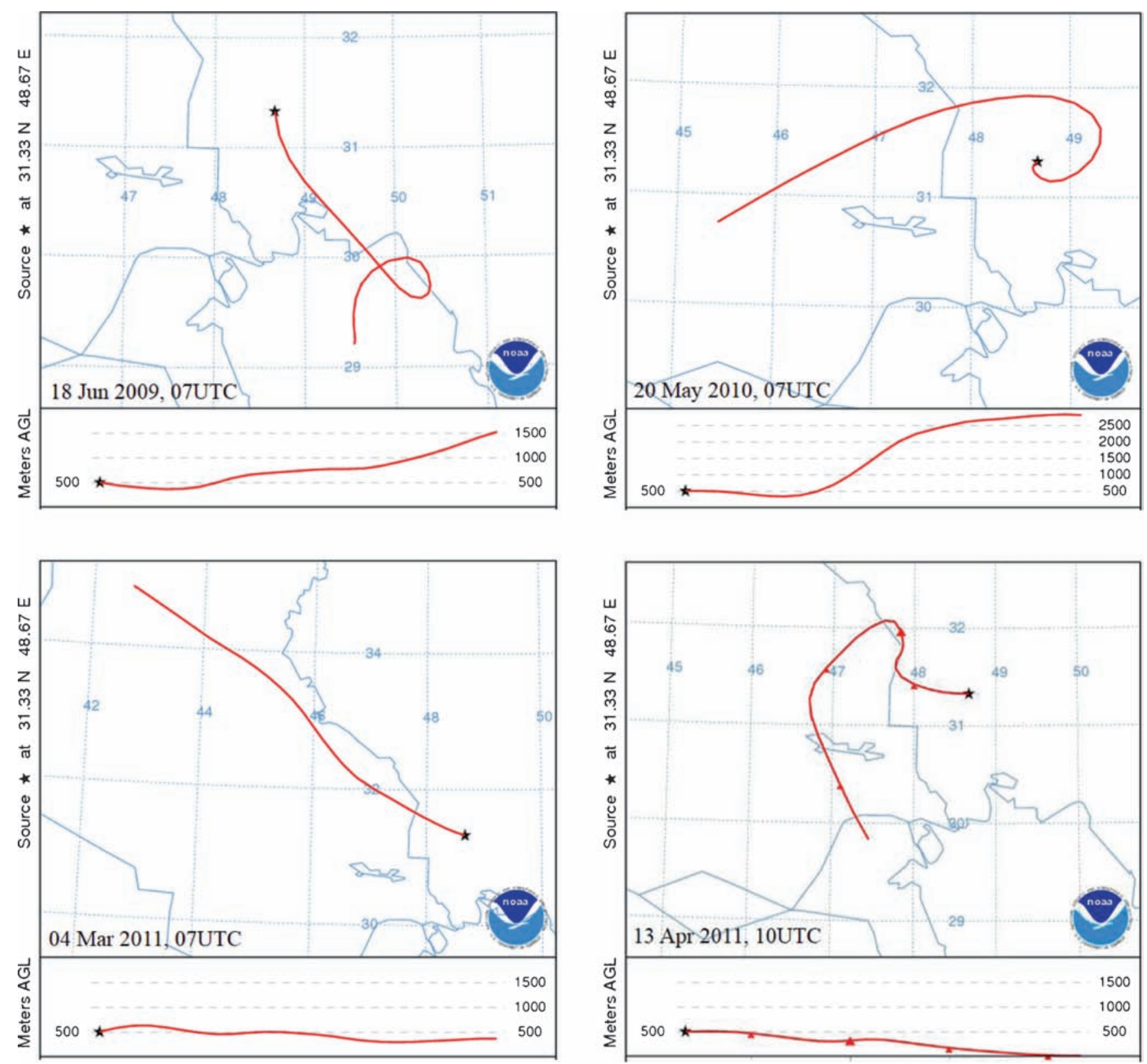

Figure 11. NOAA HYSPLIT model output backward trajectories for Ahwaz station in four dust cases.

In the case 13th April, 2011, a very strong low pressure with a centre of $1004 \mathrm{mb}$ was recognised. In this case, we had the highest dust storm in intensity. This could illustrate the cause of different dust storm situations in different dust cases. More intense low pressures could cause more intense dust situations and also long distance transports.

Backward trajectories of NOAA HYSPLIT model show how the dust travels from the source to other areas. The trajectories in figure 11 show the direction and the movement of these dust events. It is seen that these cases have different dust transport directions depending on the low pressures and also other weather conditions that directly or indirectly affect the dust transport.

\section{Discussion and conclusion}

This study focuses on dust enhancement over the arid environment of south-west Iran and surrounding areas by means of MODIS reflectance and radiance data. Two enhancement algorithms were proposed for dust detection, using MODIS data by combining visible channel radiance/reflectance with IR channel brightness temperatures. The recent method (using thermal infrared spectrum) detected dust well. Using these wavelengths for detecting dust could eliminate the atmospheres effect and give more accurate results. It should be also mentioned that as studies confirmed before, during the daytime, IR images dust clouds are 
evident over the land but not over the water. That is because they contrast well against dark (warm) land surfaces in IR images but not cool sea surfaces where they blend in. We cannot see dust over the bright land background, but it's clearly visible over the dark sea in visible images (COMET 2010). This is not in contrast with our findings because here a combination of visible and thermal infrared bands were used that could have different results than just using them. A comparison with quantitative AOD retrieval was performed to validate the enhancement algorithms. Comparing the enhanced images using IR technique with synoptic maps, MODIS AOD values, DREAM8b model outputs and synoptic stations data, it was discovered that the applied enhancement algorithms provide a valuable approach to monitor dust storms compared to MODIS AOD retrievals or model outputs. For all dust storm cases, a low pressure was the main cause of the dust storms. Using trajectory maps, we were able to track the transport of dust from the main sources. Results showed that for the dust storm occurred on 4th March 2011, the dust originated from the border of Iran and Iraq, and then moved southward towards the Persian Gulf coasts, while in the case May 20th 2010, it moved northward. This could also be seen in MODIS AOD retrievals.

In all dust cases, the second algorithm (TIR) better enhanced the dust areas, but there are still some dusty areas not enhanced in both algorithms. Therefore, generating more complicated algorithms could be suggested for future studies.

It seems that all products have some uncertainties in enhancing the dust, so finding an appropriate algorithm is necessary to enhance the affected areas. Also, having geostationary satellite data in the study region could make the estimations more accurate. The physical characteristics, composition, abundance, spatial and temporal distribution, as well as the dynamics of the global aerosols are still not well known, and new data from satellite sensors can be used to improve our current understanding and to give a boost to the effort in future climate predictions, so, current detecting algorithms could be modified.

As a conclusion, combining the satellite data and numerical prediction model can help us monitor and identify dust storms with appropriate accuracy. In order to assess the impact of dust events on human health and water resources and the damage to various sectors of the Iranian economy, additional studies with adequate modelling tools are needed.

Lastly, the dust storm enhancement product is one of the most important operational products; this product is used for the assimilation of dust forecasting models as one important data source of the initiative dust distribution field. This could be a valuable subject for researches in this field. So, attempting to build new algorithms to improve the enhancement processes would be a necessary and applicable technique.

\section{Acknowledgements}

The authors would like to thank IRIMO (Iranian Meteorological Organization) for providing observation data for this research, the MODIS rapid-fire team, MODIS Giovanni website and NCEP/NCAR for their technical assistance and useful data. Also, the authors gratefully acknowledge the NOAA Air Resources Laboratory (ARL) for the provision of the HYSPLIT transport and dispersion model and/or READY website (http://www.ready. noaa.gov) used in this publication. Images of dust model outputs are from the BSC-DREAM8b operated by the Barcelona Supercomputing Center (http://www.bsc.es/earth-sciences/mineral-dustforecast-system/). We appreciate their hard and valuable work.

\section{References}

Ackerman S A 1997 Remote sensing aerosols using satellite infrared observations; Geophys. Res. 102 17,069-17,079.

Ackerman S A, Strabala K I, Menzel W P, Frey R, Moeller C C, Gumley L E and Zhang H 2002 Discriminating clear-sky from cloud with MODIS - Algorithm Theoretical Basis Document (MOD35), ATBD Reference Number: ATBD-MOD-06. Goddard Space Flight Center, version 4.0, p. 115, NASA Goddard Space Flight Center Greenbelt, Md, shttp://eospso.gsfc.nasa.gov/ftp_ATBD/ REVIEW/MODIS/ATBD-MOD-06/atbd-mod-06.pdf.

Aeronet (Aerosol Robotic Network) 2016 Nasa Goddard Space Flight Center, http://aeronet.gsfc.nasa.gov/new_ web/aerosols.html.

Alizadeh-Choobari O, Ghafarian P and Owlad E 2015 Temporal variations in the frequency and concentration of dust events over Iran based on surface observations; Int. J. Climatol., Wiley Online Library (wileyonlinelibrary.com), doi: 10.1002/joc. 4479 .

Arakawa A and Lamb V R 1977 Computational design of the basic dynamical processes of the UCLA general circulation model; Meth. Comput. Phys., Academic Press 17 174-265.

BSC (Barcelona Supercomputing Center) 2016 BSC Mineral Dust Model Database, file:///G:/paper\%20dust/Dream/ BSC\%20Mineral\%20Dust\%20Model\%20Database\%20_ \%20BSC-CNS.htm.

Carlson T N 1979 Atmospheric turbidity in Saharan dust outbreaks as determined by analysis of satellite brightness data; Mon. Wea. Rev. 107 322-335.

COMET (Cooperative Program for Operational Meteorology, Education and Training) Mesoscale Primer, Forecasting Dust Storms, V2, University Corporation for Atmospheric Research, Copyright 2010, University Corporation for Atmospheric Research.

Dunion J P and Velden C S 2004 The impact of the Saharan air layer on Atlantic tropical cyclone activity; Bull. Am. Meteor. Soc. 85(3) 353-365. 
Edgell H S 2006 Desert dust and loess: Arabian Deserts; Nature, Origin, and Evolution, pp. 297-308.

Fécan F, Marticorena B and Bergametti G 1998 Parametrization of the increase of the aeolian erosion threshold wind friction velocity due to soil moisture for arid and semi-arid areas; Ann. Geophys. 17(1) 149-157.

Fraser R S 1976 Satellite measurement of mass of Sahara dust in the atmosphere; App. Opt. 15(10) 2471-2479.

Giorgi F 1986 A particle dry-deposition parameterization scheme for use in tracer transport models; J. Geophys. Res. Atmos. 91(D9) 9794-9806.

Guang-Yu S H I and Yuan-Long S U N 2010 Detecting aerosols over land from satellites by measuring far IR radiation from the earth-atmospheric system; Atmos. Ocean. Sci. Lett. 3(2) 111-115.

Hsu N C, Jeong M J, Bettenhausen C, Sayer A M, Hansell R, Seftor C S, Huang J and Tsay S C 2013 Enhanced Deep Blue aerosol retrieval algorithm: The second generation; Geophys. Res. Atmos. 118(16) 9296-9315.

Jamalizadeh M R, Moghaddamnia A, Piri J, Arbabi V, Homayounifar M and Shahryari A 2008 Dust storm prediction using ANNs technique (A case study: Zabol City); World Academy of Science, Engineering and Technology 43 512-520.

Janjic Z I 1984 Nonlinear advection schemes and energy cascade on semi-staggered grids; Mon. Wea. Rev. 112(6) 12341245 .

Janjić Z I 1994 The step-mountain eta coordinate model: Further developments of the convection, viscous sublayer, and turbulence closure schemes; Mon. Wea. Rev. 122(5) 927-945.

Janugani S, Jayaram V, Cabrera S D, Rosiles J G, Gill T E and Rivera N R 2009 Directional analysis and filtering for dust storm detection in NOAA-AVHRR imagery, In: SPIE Defense, Security, and Sensing; p. 73341G.

Karimi N, Moridnejad A, Golian S, Vali Samani J M, Karimi D and Javadi S 2012 Comparison of dust source identification techniques over land in the Middle East region using MODIS data; Canadian; J. Remote Sens. 38(5) 586-599.

King M, Kaufman Y, Menzel P and Tanre D 1992 Remote sensing of cloud, aerosol, and water vapor properties from the Moderate Resolution Imaging Spectrometer (MODIS); Trans. Geosci. Remot. Sens. 30(1) 2-27.

King M, Kaufman Y, Tanre D and Nakajima T 1999 Remote sensing of tropospheric aerosols from space: Past, present, and future; Bull. Am. Meteor. Soc. 80(11) 2229-2259.

Legrand M, Plana-Fattori A and N'doumé C 2001 Satellite detection of dust using the IR imagery of Meteosat: 1. Infrared difference dust index; Geophys. Res. 106 18,25118,274 .

Li X and Song W 2009 Dust storm detection based on Modis Data; International archives of photogrammetry, Remote Sensing and Spatial Information Sciences, Liaoning Technology University, Shengyang, pp. 169-172.

Lohmann U and Feichter J 2005 Global indirect aerosol effects: A review; Atmos. Chem. Phys. 5 715-737.

Lyapustin A, Wang Y, Levy R C, Remer L A, Hsu C and Reid J S 2010 A comparison between MODIS Dark Target, Deep Blue and MAIAC Aerosol Algorithms over Land; In: AGU Fall Meeting Abstracts 14.

Mashayekhi R, Irannejad P, Feichter J and Bidokhti A A 2009 Implementation of a new aerosol HAM model within the Weather Research and Forecasting (WRF) modeling system; Geosci. Model Develop. Discuss. 2 681-707.

Mesinger F, Janjić Z I, Ničković S, Gavrilov D and Deaven D 1988 The step-mountain coordinate: Model description and performance for cases of Alpine lee cyclogenesis and for a case of an Appalachian redevelopment; Mon. Wea. Rev. 167(7) 1493-1518.

Middleton N J 1986 A geography of dust storms in southwest Asia; J. Climatol. 6(2) 183-196.

Miller S D 2003 A consolidated technique for enhancing dust storms with MODIS; Geophys. Res. Lett. 30(20) 2071-2075.

Miri A, Ahmadi H, Ghanbari A and Moghaddamnia A 2007 Dust storm impacts on air pollution and public health under hot and dry climate; Int. J. Energ. Environ. 2(1) 101-105.

MODIS Level 1B Product User's Guide for Level 1B, Version 6.1.0 (Terra) and Version 6.1.1 (Aqua) MCST Document \# PUB-01-U-0202- REV C MCST Internal Memorandum \# M1054 Prepared by Members of the MODIS Characterization Support Team for NASA/Goddard Space Flight Center Greenbelt, MD 20771, February 27, 2009.

Mohammad R 2012 Using thermal infrared (TIR) data to characterize dust storms and their sources in the Middle East, Doctoral dissertation, University of Pittsburgh.

Moorthy K K, Satheesh S K, Sarin M M and Panday A K 2016 South Asian aerosols in perspective: Preface to the special issue; Atmos. Environ. 125 307-311.

NASA Dark target 2016 MODIS Aerosol Retrieval Algorithm; http://darktarget.gsfc.nasa.gov/.

NASA GES DISC (Goddard Earth Sciences Data and Information Services Center) 2017 Brightness temperature; https://disc.sci.gsfc.nasa.gov/dataholdings/PIP/ brightness_temperature.shtml.

Nickovic S, Kallos G, Papadopoulos A and Kakaliagou O 2001 A model for prediction of desert dust cycle in the atmosphere; J. Geophys. Res. 106(D16) 18,113-18,129.

Norton C C, Mosher F R, Hinton B, Martin D W, Santek D and Kuhlow W 1980 A model for calculating desert aerosol turbidity over the oceans from geostationary satellite data; J. Appl. Meteor. 19(6) 633-644.

Ramsey M and Fink J 1999 Estimating silicic lava vesicularity with thermal remote sensing: A new technique for volcanic mapping and monitoring; Bull. Volcanol. 61 32-39.

Saha A, Moorthy K K and Niranjan K 2005 Interannual variations of aerosol optical depth over coastal India: Relation to synoptic meteorology; Appl. Meteorol. 44(7) 1066-1077.

Shahraiyni H T, Karimi K, Nokhandan M H and Moghadas N H 2015 Monitoring of dust storm and estimation of aerosol concentration in the Middle East using remotely sensed images; Arabian J. Geosci. 8(4) 2095-2110.

Shao Y and Dong C H 2006 A review on east Asian dust storm climate, modelling and monitoring; Global Planet. Change 52(1) 1-22.

Shao Y, Raupach M R and Findlater P A 1993 Effect of saltation bombardment on the entrainment of dust by wind; J. Geophys. Res. Atmos. 98(D7) 12,719-12,726.

Shenk W E and Curran R J 1974 The detection of dust storms overland and water with satellite visible and infrared measurements; Mon. Wea. Rev. 102 830-837.

Stevens B and Feingold G 2009 Untangling aerosol effects on clouds and precipitation in a buffered system; Nature $461607-613$.

Taghavi F 2015 Remote and regional sources of dust and its impact on the environment. Case studies: Urmia and Ahvaz cities, Workshop on Environmental and Water Resource Management Issues of Inland Lakes, Irvine, CA, USA.

Taghavi F and Asadi A 2008 The Persian Gulf 12th April dust storm Observation and Model analysis, 2008 EUMETSAT Meteorological Satellite Conference Proceedings, Darmeschtad, Germany, 52p.

Taghavi F and Mohammadi H 2008 The survey of linkage between climate changes and desertification using extreme climate index software; Desert 13(1) 9-17. 
Thomas D S G 1997 Arid zone geomorphology, 2nd edn, Wiley, 732p.

Wald A E, Kaufman Y J, Tanré D and Gao B C 1998 Daytime and nighttime detection of mineral dust over desert using infrared spectral contrast; Geophys. Res. 03(D24) 32307-32313.

Washington R, Todd M, Middleton N J and Goudie A S 2003 Dust-storm source areas determined by the total ozone monitoring spectrometer and surface observations; Ann. Assoc. Am. Geogr. 93(2) 297-313.
Xu H, Cheng T, Xie D, Li J, Wu Y and Chen H 2014 Dust identification over arid and semiarid regions of Asia using AIRS thermal infrared channels; Adv. Meteorol., Article ID 847432, 16p, doi: 10.1155/2014/847432.

Zhang P, Lu N M, Hu X Q and Dong C H 2006 Identification and physical retrieval of dust storm using three MODIS thermal IR channels; Global Planet. Change 52(1) 197-206.

Zhao T X-P, Ackerman S and Guo W 2010 Dust and smoke detection for multi-channel imagers; Remote Sens. 2 2347-2367.

MS received 7 February 2016; revised 13 September 2016; accepted 17 October 2016

Corresponding editor: K KRISHNAMOORTHY 